\title{
Atrophic gastritis and Helicobacter pylori infection in outpatients referred for gastroscopy
}

\author{
A Oksanen, P Sipponen, R Karttunen, A Miettinen, L Veijola, S Sarna, H Rautelin
}

Herttoniemi Municipal Hospital, FIN-00800 Helsinki, Finland

A Oksanen

L Veijola

Department of Pathology, Jorvi Hospital, FIN-02740

Espoo, Finland

P Sipponen

Department of Medical Microbiology, University of Oulu, FIN-90220 Oulu,

Finland

R Karttunen

Department of Bacteriology and Immunology,

Haartman Institute, University of Helsinki and Helsinki

University Central Hospital Diagnostics, FIN-00014 Helsinki,

Finland

A Miettinen

H Rautelin

Department of Public Health, University of Helsinki, FIN-00300 Helsinki, Finland S Sarna

Correspondence to: Dr Hilpi Rautelin, Department of Bacteriology and Immunology, PO Box 21, FIN-00014 University of Helsinki, Finland

Accepted for publication 20 October 1999

\begin{abstract}
Background-Atrophic gastritis has been shown to be one of the long term sequelae of Helicobacter pylori infection.

Aims-To determine the prevalence of atrophic gastritis in outpatients, to study the accuracy of serological methods for revealing atrophy, and to define the association of $H$ pylori infection with atrophic gastritis in these patients.

Patients/methods-A total of 207 consecutive outpatients referred for gastroscopy were included. Biopsy specimens from the antrum and corpus were assessed histologically according to the Sydney system. Serum samples were studied for $\mathrm{H}$ pylori IgG and IgA antibodies by enzyme immunoassay, CagA antibodies by immunoblot, pepsinogen I by an immunoenzymometric assay, gastrin by radioimmunoassay, and parietal cell antibodies by indirect immunofluorescence.
\end{abstract}

Results-Histological examination revealed atrophic gastritis in $52(25 \%)$ of 207 patients. $H$ pylori and CagA antibodies were strongly associated with atrophic antral gastritis but poorly associated with atrophic corpus gastritis. Low serum pepsinogen I was the most sensitive and specific indicator of moderate and severe atrophic corpus gastritis. All six patients with moderate atrophic corpus gastritis had $H$ pylori infection but eight of 10 patients with severe atrophic corpus had increased parietal cell antibodies and nine had no signs of $\boldsymbol{H}$ pylori infection.

Conclusions-Atrophic antral gastritis was strongly associated with CagA positive $H$ pylori infection. Severe atrophic corpus gastritis was not determined by $\boldsymbol{H}$ pylori tests but low serum pepsinogen I, high gastrin, and parietal cell antibodies may be valuable in detecting these changes.

(Gut 2000;46:460-463)

Keywords: Helicobacter pylori; atrophic gastritis; CagA antibodies; Helicobacter pylori antibodies; pepsinogen; parietal cell antibodies

Gastric atrophy was first recognised in 1870 in postmortem samples of a patient with pernicious anaemia, ${ }^{1}$ and thereafter corpus dominant atrophic autoimmune gastritis associated with pernicious anaemia has become a well known condition. ${ }^{2}$ Since the development of fibregastroscopy techniques, the gastric mucosa has become easier to study in living subjects. The recognition and culture of
Helicobacter pylori ( $H$ pylori) has largely changed the understanding of the aetiology of gastritis $^{3}$ and atrophic gastritis has been shown to be a consequence of long term gastritis caused by $\mathrm{H}$ pylori. ${ }^{4}$ However, gastric autoantibodies have also been demonstrated in subjects with $H$ pylori positive gastritis, ${ }^{5}$ and a question has arisen of whether or not $H$ pylori also plays a role in the aetiology of autoimmune type atrophic gastritis. ${ }^{6}$

Atrophic changes of the corpus can be determined by blood tests, such as low serum pepsinogen I, high serum gastrin, and parietal cell antibodies. ${ }^{7}$ In the present study, different serological markers of atrophic gastritis and $H$ pylori infection were measured in 207 consecutive patients who underwent gastroscopy at an outpatient clinic. The objectives of the study were to determine the prevalence of atrophic gastritis in outpatients referred for endoscopy, to study the accuracy of different serological methods in revealing atrophic gastritis in these patients, and to determine to which type of atrophic gastritis $H$ pylori infection is associated.

\section{Patients and methods}

PATIENTS

A total of 207 consecutive adult outpatients (age range 19-83 years; median 55 years; 122 women) referred to the Helsinki Municipal Hospital at Herttoniemi for upper endoscopy between October 1996 and March 1997 were included. Patients previously participated in a study evaluating a new $H$ pylori rapid diagnostic test. ${ }^{8}$ Only those who had not had prior helicobacter eradication therapy were included.

\section{ENDOSCOPY AND HISTOLOGY}

Endoscopies were performed by two of the authors (AO, LV). Two biopsy specimens for histological examination were obtained from the antrum and the corpus (both the anterior and posterior walls of each). The biopsy specimens were stained with haematoxylin-eosin, Alcian blue ( $\mathrm{pH}$ 2.5)-periodic acid-Schiff, and modified Giemsa stains. The specimens were examined in a blinded manner by a pathologist (PS) and scored in accordance with the Sydney system. ${ }^{9}$ The presence of $H$ pylori, chronic and acute gastritis, atrophy (loss of proper glands), and intestinal metaplasia were scored 0-3 (none, mild, moderate, or severe) for the antrum and corpus separately.

Abbreviations used in this paper: $H$ pylori, Helicobacter pylori; EIA, enzyme immunoassay; IgG, IgA, immunoglobulins $\mathrm{G}$ and $\mathrm{A}$. 
Table 1 Number of patients with atrophic gastritis and positive results in the following tests: elevated $H$ pylori antibodies of Ig $G$ andlor IgA class ( $H$ pylori antibodies), low serum pepsinogen I level ( $<28 \mu \mathrm{g} / \mathrm{ml}$; Low Peps I), high serum gastrin level ( $>111 \mathrm{pg} / \mathrm{ml}$; High gastrin), parietal cell antibodies (PCA) and CagA antibodies (CagA). Atrophy was graded as none (0), mild (1), moderate (2), or severe (3)

\begin{tabular}{lllrlrrr}
\hline & $\begin{array}{l}\text { Atrophy } \\
\text { grade }\end{array}$ & $\begin{array}{l}\text { H pylori } \\
\text { antibodies }\end{array}$ & $\begin{array}{l}\text { Low } \\
\text { Peps I }\end{array}$ & $\begin{array}{l}\text { High } \\
\text { gastrin }\end{array}$ & PCA & CagA & Total \\
\hline Antrum atrophy & 0 & 58 & 11 & 14 & 14 & 49 & 171 \\
& 1 & 22 & 4 & 6 & 3 & 20 & 30 \\
& 2 & 4 & 0 & 1 & 0 & 4 & 4 \\
Corpus atrophy & 3 & 2 & 0 & 0 & 0 & 2 & 2 \\
& 0 & 69 & 1 & 6 & 7 & 62 & 179 \\
& 1 & 10 & 1 & 2 & 1 & 7 & 11 \\
& 2 & 6 & 3 & 2 & 1 & 4 & 6 \\
& 3 & 0 & 10 & 10 & 8 & 1 & 10 \\
\hline
\end{tabular}

SEROLOGICAL TESTS

Blood was obtained from each patient during the visit to the endoscopy unit. Separated serum samples were stored at $-20^{\circ} \mathrm{C}$ until analysed. Immunoglobulin $\mathrm{G}$ (IgG) and IgA antibodies to $H$ pylori were measured separately using an inhouse enzyme immunoassay (EIA). ${ }^{10}$ The antigen used was an acid glycine extract from $H$ pylori strain NCTC 11637. Absorbance readings were converted to reciprocals of the end point titres. The end point titres were dilutions of serum at the cut off level defined by the optical densities of positive reference serum pools at constant dilutions. Separate reference pools were used for IgG and IgA. Serum gastrin concentrations were measured using a radioimmunoassay kit (ICN Pharmaceuticals, Diagnostics Division, USA). The antibody of the kit recognises the major circulating forms of gastrin. According to the manufacturer's instructions, the expected normal range of gastrin in healthy volunteers aged $19-60$ years is $25-111 \mathrm{pg} / \mathrm{ml}$ (mean 49.6 $\mathrm{pg} / \mathrm{ml}$ ). Serum pepsinogen I concentrations were measured using an immunoenzymometric assay (Gastroset PG1, Orion Diagnostica, Espoo, Finland). The expected range for pepsinogen $\mathrm{I}$ in healthy volunteers is $28-158$ $\mu \mathrm{g} / 1$ (mean $84.4 \mu \mathrm{g} / \mathrm{l})$.

CagA antibodies were determined using an immunoblot method. CagA antigen was prepared from NCTC 11637 strain by harvesting the bacteria in Tris $\mathrm{HCl}$ buffer $10 \mathrm{mM}$ in a stock solution of $7.7 \mu \mathrm{g}$ protein $/ \mu \mathrm{l}$. Bacterial suspension was run in a $7.5 \%$ SDS-PAGE gel. Proteins were transferred to a nitrocellulose membrane at $4^{\circ} \mathrm{C}$ overnight using a blotting device. The CagA protein band was confirmed using a specific rabbit anti-CagA antibody (a gift from Dr Martin Blaser). Strips were incubated with serum samples, diluted 1:100. After washing, they were treated with antihuman IgG conjugated horseradish peroxidase (Dako, Glostrup, Denmark) and the substrate diaminobenzidine. Positive bands were estimated visually. CagA antibodies were tested blindly.

Parietal cell antibodies were studied using an indirect immunofluorescence technique with unfixed cryostat sections ( $5 \mu \mathrm{m}$ thick) of a tissue block as substrate, as previously described. ${ }^{11}$ The block contained the following tissues: mouse stomach, rat stomach, rat kidney, and mouse liver. Sera were screened at 1:10 dilutions. Sera staining mouse parietal cells were regarded as positive and titrated fur- ther. The last dilution at which unequivocal staining was seen was taken as the end point titre.

STATISTICAL ANALYSIS

Fisher's exact test was used to compare the proportions of different characteristics between groups, and $\mathrm{p}$ values $<0.05$ were considered statistically significant. The MannWhitney exact test was used to compare histological features between CagA positive and negative groups. Calculations were performed using StatXact 3 for Windows (Statistical Software for Exact Nonparametric Inference; Cytel Software Corporation 1995, Cambridge Massachusetts, USA).

\section{Results}

A total of 52 patients (age range 34-83 years; median age 67 years; 33 (63\%) women) had atrophic gastritis. In 24 patients, atrophic gastritis was seen only in the antrum, in 16 patients only in the corpus, and in 11 patients both areas were affected. Corpus biopsies were not available for one patient with moderate atrophic antral gastritis. Of the 27 patients with atrophic corpus gastritis, 16 patients had intestinal metaplasia in the corpus also (the grade of metaplasia being the same (six patients), or one (nine patients) or two (one patient) grades lower than that of the atrophy grade). All 36 patients with atrophic antral gastritis had intestinal metaplasia which, in 35 cases was the same grade as that of atrophy.

Seventy seven patients had helicobacters on histological examination and 31 of these $(40 \%$; age range $38-83$ years; median age 66 years; 21 women) had atrophic gastritis in the antrum or in the corpus, while only 21 (16\%; age range $38-82$ years; median age 68 years; 12 women) of the 130 histologically helicobacter negative patients had any atrophic changes $(p=0.0002)$. Of the $31 H$ pylori positive patients with atrophic gastritis, atrophic changes (mild or moderate) were seen in the antrum only in 17 patients. In five patients, atrophic gastritis (mild or moderate) was detected in the corpus only whereas in eight patients, including two patients with severe atrophic antral gastritis and intestinal metaplasia, atrophic changes were seen in both the antrum and corpus. Six patients (age range 54-83 years; median age 67 years) with histologically detected $H$ pylori had moderate atrophic gastritis in the corpus. Table 1 gives the number of patients with different grades of atrophic changes. Atrophic antral gastritis was found significantly $(p=0.0001)$ more often in $H$ pylori positive than in $H$ pylori negative patients irrespective of whether or not the infection was verified by histology or by increased $H$ pylori antibodies. Of the 21 histologically helicobacter negative patients with atrophic changes, five patients with increased $H$ pylori IgG antibodies had only mild atrophic gastritis.

Severe atrophic corpus gastritis (total loss of normal oxyntic glands and parietal cells) was detected in 10 patients (age range 50-82 years; median age 70 years; five women). They showed no histological or serological evidence 
Table 2 Sensitivity (Sens), specificity (Spec), and positive (PPV) and negative (NPV) predictive values of tests for the detection of moderate (grade 2) and severe (grade 3) atrophic corpus gastritis in 207 consecutive adult patients referred for gastroscopy

\begin{tabular}{lllll}
\hline & $\%$ Sens & $\%$ Spec & $\% P P V$ & $\% N P V$ \\
\hline Serum pepsinogen I <28 $\mu \mathrm{g} / 1$ & 81 & 99 & 87 & 98 \\
Serum gastrin >111 pg/ml & 75 & 96 & 60 & 98 \\
Parietal cell antibodies & 56 & 96 & 53 & 96 \\
H pylori antibodies (IgG and/or IgA) & 38 & 58 & 8 & 92 \\
CagA antibodies & 31 & 64 & 7 & 92 \\
\hline
\end{tabular}

of $H$ pylori infection, except for one patient with a positive CagA result (table 1). In six of these patients, the antrum showed normal histology. All 10 patients with severe atrophic corpus gastritis (table 1) had low serum pepsinogen I values (range 5-19 $\mu \mathrm{g} / \mathrm{l}$ ) and high serum gastrin levels (range 361-1097 pg/ml; upper normal limit $111 \mathrm{pg} / \mathrm{ml})$, and parietal cell antibodies were present (antibody titre range 2506251; median 750) in eight (five women, three men). Vitamin B12 levels were below the lower limit of normal in nine of 10 patients. In addition, parietal cell antibodies were detected in nine more patients (antibody titre range 50-6251; median 250), all women, eight of whom had helicobacters on histological examination and six had no atrophy; one patient showed normal gastric histology. Parietal cell antibodies were associated with female sex both in the whole study group $(\mathrm{p}=0.0431)$ and in the $H$ pylori positive patient group $(\mathrm{p}=0.0198)$. In addition, parietal cell antibodies were significantly associated with the presence of atrophic gastritis in all 207 patients $(p=0.0004)$ but not in the helicobacter positive group. Table 2 shows the accuracy of the different serological tests in detecting severe or moderate atrophic corpus gastritis. Low serum gastrin levels were detected in 20 patients, 16 of whom had normal gastric histology.

Eleven patients had atrophic changes in the antrum and corpus. Three patients with severe atrophic corpus gastritis had mild atrophic changes in the antrum. None of these patients showed signs of $H$ pylori infection whereas two had parietal cell antibodies. All of the eight more patients with atrophic changes in both the antrum and corpus had helicobacters on histological examination and none had parietal cell antibodies. Two patients had severe atrophic antrum gastritis and moderate or mild atrophic changes in the corpus; one had moderate atrophic antrum gastritis and mild atrophic changes in the corpus, and two had moderate atrophic corpus gastritis with only mild atrophic changes in the antrum. Three more patients had only mild atrophic changes in both the antrum and corpus.

CagA antibodies were found in 61 (79\%) helicobacter positive patients on histology. In addition, five histologically helicobacter negative patients with elevated $H$ pylori IgG antibodies had positive CagA serology. Furthermore, nine patients with neither helicobacters on histological examination nor elevated $H$ pylori antibodies on EIA showed positive CagA serology. Of the latter, five had normal gastric histology. Among helicobacter positive patients determined by histology, atrophic antral gastritis was more common in
CagA positive than in CagA negative subjects $(p=0.0462)$ but no such association was found between CagA positivity and atrophic changes in the corpus $(\mathrm{p}=0.8178)$. Furthermore, CagA positive patients had higher scores for polymorphonuclear $(p=0.0164)$ but not for mononuclear infiltration $(p=0.0575)$ in the antrum. No such association was found between CagA positivity and inflammatory scores of the corpus or with helicobacter density in the antrum or corpus. All 12 duodenal ulcer patients had positive CagA serology, but of the five histologically helicobacter positive patients with gastric ulcers, only three showed CagA antibodies.

\section{Discussion}

In agreement with previous studies, ${ }^{4}{ }^{12}$ atrophic gastritis was more common in helicobacter positive than negative patients in our study group. However, as atrophic changes in the corpus and antrum were measured separately, $H$ pylori positivity, verified either by serology or histology, was strongly associated only with atrophic antral gastritis. Only after exclusion of 10 patients with severe atrophic corpus gastritis was $H$ pylori infection associated with atrophic changes in the corpus also.

The relationship between $H$ pylori infection and severe atrophic corpus gastritis with or without pernicious anaemia is debatable. In many studies, patients with pernicious anaemia rarely, if ever, have serological or histological signs of $H$ pylori infection. ${ }^{13-15}$ In a Swedish study, however, $83 \%$ of patients with pernicious anaemia had antibodies against $H$ pylori. ${ }^{16}$ Before the era of $\mathrm{H}$ pylori, first degree relatives of patients with pernicious anaemia were shown to have more corpus but not antrum atrophy than controls. ${ }^{17}$ Even if atrophic antral gastritis is regarded as a direct result of $H$ pylori infection, factors other than $H$ pylori could play a role in the development of severe atrophic corpus gastritis and pernicious anaemia. More recently it has been shown ${ }^{18}$ that in patients without pernicious anaemia (normal vitamin B12 levels) the prevalence of $H$ pylori antibodies was lower in those with more severe atrophy probably because of the disappearance of $H$ pylori infection after progression of atrophy and hypochlorhydria.

In our 10 patients with severe atrophic corpus gastritis, there were no signs of current or past $H$ pylor $i$ infection, with the exception of one patient with positive CagA serology. At least two of the following three tests were positive in all 10 patients: low pepsinogen I, high gastrin level, and parietal cell antibodies. These patients appeared to form a distinct group and to differ from those six $H$ pylori positive patients with moderate atrophic corpus gastritis, although some of the latter also had low pepsinogen I and high gastrin levels. There was no significant difference in the median ages of these two groups, as would be expected if severe atrophic corpus gastritis were regarded solely as an end stage of the progressing $H$ pylori gastritis.

$\mathrm{H}$ pylori infection was shown to be associated with atrophic corpus gastritis only after exclusion of 10 patients with $H$ pylori negative 
severe atrophic corpus gastritis. Thus a large number of patients with pernicious anaemia may mask the association of $H$ pylori gastritis and atrophic corpus gastritis. This may be especially so in Northern European countries where the prevalence of pernicious anaemia, probably of genetic origin, ${ }^{19}$ is considerably higher than in many other countries. ${ }^{20}$ In a Finnish random sample representing the population of Southern Finland, 1.4\% of individuals had severe atrophic corpus gastritis with no atrophic changes in the antrum, whereas $11 \%$ had atrophic gastritis in the antrum only or in both the antrum and corpus. ${ }^{21}$ In our study, the prevalence of severe atrophic corpus gastritis was considerably higher than in the random sample material. This is understandable as our study included some patients who had been referred for gastroscopy because of low serum vitamin B12 levels.

cagA positive $H$ pylori strains have been shown to cause more severe gastritis than cagA negative strains, ${ }^{22}$ and patients infected with cagA positive strains may also be more susceptible to peptic ulcers. ${ }^{23}$ Gastric cancer ${ }^{24}{ }^{25}$ is more common in those infected with cagA positive strains. It has been shown that atrophic corpus gastritis develops more often in CagA positive than in CagA negative patients. ${ }^{26}$ In addition, a clear correlation between atrophic antral gastritis and CagA seropositivity has been demonstrated. ${ }^{27}$ In the present study, among helicobacter positive patients, CagA positivity was not associated with atrophic gastritis in the corpus but was associated with atrophic antral gastritis. In agreement with our results, CagA seropositivity correlated with atrophic antral gastritis but not with atrophic corpus gastritis in an earlier UK study. ${ }^{28}$ It is uncertain why in our study nine patients with neither helicobacters on histological examination nor elevated $H$ pylori antibodies on EIA had a positive CagA value. This may be a false positive result because of cross reactive antibodies to CagA. In contrast, it has been suggested that CagA antibody measurement using immunoblotting may be more sensitive than EIA in showing past $H$ pylori infection in some individuals. ${ }^{29}$

In conclusion, atrophic gastritis was detected in $25 \%$ of consecutive outpatients referred for upper endoscopy. Moderate or severe atrophic corpus gastritis was found in 16 patients. Low serum pepsinogen I levels showed a sensitivity of $81 \%$ and specificity of $99 \%$ in detecting moderate or severe atrophic corpus gastritis, whereas high serum gastrin levels and the presence of parietal cell antibodies had high specificity $(96 \%)$ but low sensitivity $(75 \%$ and $56 \%$, respectively). None of the blood tests reliably detected atrophic antral gastritis. $H$ pylori and CagA antibodies were significantly associated with atrophic antral gastritis, whereas patients with severe atrophic corpus gastritis, most of whom had parietal cell antibodies, showed no signs of $H$ pylori infection.

Our study was supported in part by Orion Diagnostica, Espoo, Finland, and the Yrjö Jahnsson Foundation, Helsinki, Finland.
We thank Mr Jarmo Ramberg for help in the measurement of serum gastrin. The skilful technical assistance of Ms Eila Kelo is gratefully acknowledged.

1 Fenwick S. On atrophy of the stomach. Lancet $1870 ; 2 \cdot 78$ 80.

2 Strickland RG, Mackay IR. A reappraisal of the nature and significance of chronic atrophic gastritis. Dig Dis Sci 1973; 18:426-40.

3 Warren JR, Marshall B. Unidentified curved bacilli on gastric epithelium in active chronic gastritis. Lancet 1983;i: 1273-5.

4 Kuipers EJ, Uyterlinde AM, Pena AS, et al. Long-term sequelae of Helicobacter pylori gastritis, Lancet 1995:345: 1525-8.

5 Clayes D, Faller G, Appelmelk BJ, et al. The gastric H+, K+ ATPase is a major autoantigen in chronic Helicobacter pylori gastritis with body mucosa atrophy. Gastroenterology 1998;115:340-7.

6 Kuipers EJ, Klinkenberg-Knol EC, Vandenbroucke-Grauls CMJE, et al. Role of Helicobacter pylori in the pathogenesis of atrophic gastritis. Scand F Gastroenterol 1997;32 (suppl 223):28-34

7 Varis K, Samloff IM, Ihamäki T, et al. An appraisal of tests for severe atrophic gastritis in relatives of patients with pernicious anemia. Am ₹ Dig Dis 1979;24:187-91.

8 Oksanen A, Veijola L, Sipponen P, et al. Evaluation of Pyloriset Screen, a rapid whole-blood diagnostic test for
Helicobacter pylori infection. $\mathcal{F}$ Clin Microbiol 1998;36:9557.

9 Price AB. The Sydney System: histological division. 7 Gastroenterol Hepatol 1991;6:209-22.

10 Kosunen, TU, Seppälä K, Sarna S, et al. Diagnostic value of decreasing IgG, IgA, and IgM antibody titres after eradication of Helicobacter pylori. Lancet 1992;339:893-5.

11 Kurki P, Linder E, Miettinen A, et al. Tissue antibodies in malignant and benign urogenital disease. Int $\mathcal{F}$ Cancer 1977;19:332-6.

12 Kawaguchi $\mathrm{H}$, Haruma K, Komoto K, et al. Helicobacter pylori infection is the major risk factor for atrophic gastritis. pylori infection is the major risk factor

13 Flejou JF, Bahame P, Smith AC, et al. Pernicious anaemia and Campylobacter like organisms; is the gastric antrum resistant to colonisation? Gut 1989;30:60-4

14 Fong TL, Dooley CP, Dehesa M, et al. Helicobacter pylori infection in pernicious anemia: A prospective controlled study. Gastroenterology 1991;100:328-32.

15 Haruma K, Komoto K, Kawaguchi H, et al. Pernicious anemia and Helicobacter pylori infection in Japan: Evaluation in a country with a high prevalence of infection. Am $\mathcal{F}$ Gastroenterol 1995;90:1107-10.

16 Ma JY, Borsch K, Sjöstrand E, et al. Positive correlation between $\mathrm{H}, \mathrm{K}$-adenosine triphosphatase autoantibodies and Helicobacter pylori antibodies in patients with perniand Helicobacter pylori antibodies in patients with per

17 Varis K, Ihamäki T, Härkönen M, et al. Gastric morphology, function and immunology in first-degree relatives of probands with pernicious anaemia and controls. Scand $\mathcal{F}$ Gastroenterol 1979,14:129-39.

18 Karnes WE Jr, Samloff IM, Siurala M, et al. Positive serum antibody and negative tissue staining for Helicobacter pylori in subjects with atrophic body gastritis. Gastroenterology 1991;101:167-74.

19 Varis K, Ihamäki T, Härkönen $M$, et al. Gastric morphology, function and immunology in first-degree relatives of probands with pernicious anaemia and controls. Scand 7 Gastroenterol 1979;14:129-39.

20 Heatley RV, Wyatt JI. Gastritis and duodenitis. In: Haubrich WS, Schaffer F, eds. Bockus gastroenterology. Philadelphia: Saunders, 1995:646-8

21 Kekki M, Siurala M, Varis K, et al. Classification principles and genetics of chronic gastritis. Scand 7 Gastroenterol 1987;22 (suppl 141):1-28

22 Yamaoka Y, Kita $M$, Kodama $T$, et al. Induction of various cytokines and development of severe mucosal inflammation by cagA gene positive Helicobacter pylori strains. Gut 1997;41:442-51.

23 Cover TL, Glupczynski Y, Lage AP, et al. Serologic detection of infection with cagA+ Helicobacter pylori strains. 7 Clin Microbiol 1995;33:1496-500.

24 Blaser MJ, Perez-Perez GI, Kleanthous H, et al. Infection with Helicobacter pylori strains possessing CagA is associated with an increased risk of developing adenocarcinoma of the stomach. Cancer Res 1995;55:2111-15.

25 Parsonnet J, Friedman GD, Orentreich N, et al. Risk for gastric cancer in people with CagA positive or CagA negative Helicobacter pylori infection. Gut 1997;40:297-301.

26 Kuipers EJ, Perez-Perez G I, Meuwissen SG M, et al. Helicobacter pylori and atrophic gastritis: Importance of the cagA status. F Natl Cancer Inst 1995;87:1777-80.

27 Sozzi M, Valentini M, Figura N, et al. Atrophic gastritis and intestinal metaplasia in Helicobacter pylori infection: The role of CagA status. Am f Gastroenterol 1998;93:375-9.

28 Crabtree JE, Wyatt JI, Perry S, et al. CagA seropositive Helicobacter pylori infected non-ulcer patients have increased frequency of intestinal metaplasia. Gut 1996;38 (suppl 1):A3.

29 Crabtree JE, Wyatt JI, Sobala GM, et al. Systemic and mucosal humoral responses to Helicobacter pylori in gastric cancer. Gut 1993;34:1339-43. 